Journal of Social Sciences 5 (4): 377-380, 2009

ISSN 1549-3652

(C) 2009 Science Publications

\title{
Creating and Developing a Service Network of Stage Costume Business in Isan Community
}

\author{
${ }^{1}$ Ourarom Chantamala, ${ }^{2}$ Suphanni Luaboonchu and ${ }^{3}$ Terdchai Pantachi \\ ${ }^{1}$ Faculty of Fine and Applied Arts, Mahasarakham University, Khamriang Campus, \\ Khantharawichai Mahasarakham, 44150, Thailand \\ ${ }^{2}$ College of Music, Mahasarakham University, Khamriang Campus, \\ Khantharawichai Mahasarakham, 44150, Thailand \\ ${ }^{3}$ Yasothon Pittayakhom School, Cheangsanit Road, Tambon Nai Mueaneg, Amphoe Mueang, \\ Yasothon Province 35000, Thailand
}

\begin{abstract}
Problem statement: A lot of stage costume businesses in Isan community (northeast community of Thailand) cannot expand their business into larger scales because the owners mange everything by themselves so it cause a lot of difficulties such as a lack of low cost stage costume sources. Approach: This research aimed to examine 3 points. First, to examine the background of stage costume business in Isan community in the past. Second, to examine the situation and difficulties of stage costume business in Isan community at present. And third, to examine the creation and development of a network of stage costume business in Isan Community. The data were collected by a literature survey, an observation and an interview in the field. The research areas were the districts of Maha Sarakham, Roi Et and Yasothon Province. A total of 15 shops were selected from 5 shops of each province and each shop had carried forward more than 5 years. The results were presented according to research purposes by means of a descriptive analysis. Results: The results revealed that the background of stage costume business of Isan community in the past began with people made costume themselves for dressing during a festival or traditional celebration. Since 1982 educational institutes have arranged learning activities on music and dramatic arts. Each of them has revived ancient tradition and art, performed both Thai and folk dramatic art. Thus stage costume business have started widely for serving the business have started widely for serving the public since then. The main situation and difficulty of stage costume business in Isan Community was the owners managed everything by themselves that caused a loss of stage costume, a lack of assistance, a lack of low cost costume sources, a competition in business and loan raising and a difficult in business expansion. The creation and development of a service network of stage costume business in Isan community was a step-by-step network. It started from the cooperation in business goal and difficulties solution of a small group of entrepreneurs. Since then, they have shared and solved the problems together and developed their network from a local scale into a country scale in order to add a profit from business operation. Conclusion/Recommendations: According to the research results, the main difficulty of stage costume business in Isan society was the entrepreneurs could not expand their business into larger scales while the requirement of customers was increasing. The researcher would like to suggest that the research concerning the ways to establish and develop a service network of stage costume business is necessary. And the entrepreneurs should establish their business network in order to share all resources together and expand their business into larger scales base on appropriate culture that enhance the sustained occupations and earnings of community.
\end{abstract}

Key words: Creating a service network, developing a service network, stage costume business

\section{INTRODUCTION}

Dramatic art or play performances are the ones of human ways of life. They play a role in the transitional rituals of human life circle such as a ritual of human life circle such as a ritual of birth, a ritual of age transition, a ritual of ailment cure and a ritual of death in order to enhance morale and provide entertainment for

Corresponding Author: Ourarom Chantamala, Faculty of Fine and Applied Arts, Mahasarakham University, Khamriang Campus, Khantharawichai Mahasarakham, 44150, Thailand 
concerned people. Especially, in Isan society (northeast society of Thailand) dramatic art and play performances are necessary for the festival of 12 month traditions. Moreover dramatic art or play was integrated into community activities such as a parade of each tradition, an activity of educational institute. for enhancing an aesthetic atmosphere and a perfection of activity ${ }^{[1]}$.

Isan community where the people believe firmly in traditions. Is reflected well in a candle festival of Buddhist Len, a sky rocket festival, Boon $\mathrm{Pa}$ Ves festival (The festival of the last rebirth of the Bodhisattva), Boon Berk Fa festival (The festival for thanking the god of rain), Boon Malai festival (The festival of a sermon listening). All people cooperate to hold a traditional festival and festival parade. In the past people dressed themselves with the clothes that they wove and participated in a traditional parade. Latterly, the parade was held for competition so people must select extra costume that go along with a kind of parade. Thus, they hired from customer shops or made parade costume. Stage costume business have carried forward more than 30 years by began with salons, tailors or dressmakers and develop to stage costume and salons for community service. Because of a lack of loan raising, a lack of cooperation among the entrepreneurs and a limit of stage costume production that caused each of the entrepreneurs could not expand his own business according to customer requirements, so he gained a small amount of profits.

Thus, the entrepreneurs should cooperate all resources together and establish a Business network in order to respond adequately customer requirements. By this link they can widely service both a customer requirement of Thai dramatic art costume and folk dramatic art costume. Moreover, this network enhances many occupations in community such as tailors, dressmakers, ornament makers, salons and others. Sequentially, these occupations are handed down from one generation to another generation and become an occupational network that encourages stage costume businesses. If a stage costume service network links together with an occupational network will cause a positive effect for community economy, community currency and community culture.

\section{MATERIALS AND METHODS}

Population and sample: Amphoe Mueang (Mueang Districts) of Mahasarakham, Roi Et and Yasothon Province.

Research methods: A total of 15 stage-costume shops was selected from 5 shops of each province and each shop had carried forward more than 5 years. The results were presented according to research purposes by means of a descriptive analysis.

\section{RESULTS}

The background of stage costume business in Isan Community in the past began with people in Isan community made costume themselves for dressing during a festival or traditional celebration. Since 1982 educational institutes have arranged learning activities on music and dramatic arts. Each of educational institutes has revived ancient tradition and art, performed both Thai and folk dramatic art. Because of a specific detail of stage costume and a lack of hired stage costume sources, thus stage costume businesses have widely started for servicing the public since then. Stage costume business in Isan community divided into 2 types: (1) stage costumer business that serviced such as hired costume together with face-makeup and hair dressing or hired costume together with dramatic art teaching (2) stage costume business that serviced such as traditional Thai costume, traditional Thai-Isan costume and wedding costume.

The situation and difficulty of stage costume business in Isan community was the owners managed everything by themselves such as searching for stage costume, investing in business, planning marketing strategies, so it caused a loss of stage costume sources, a competition in business and loan raising and a difficulty in business expansion.

The creation and development of a network of stage costume business in Isan Community was a stepby-step network. It began with the entrepreneurs of stage costume business cooperated together in a small group in order to solve the difficulties concerning business management and they applied the cooperated solutions to solving problem in business effectively, hence they expanded this network into a larger network for contacting and supporting an exchange of information with the others. At present, they have expanded their network from a local scale into a country scale.

\section{DISCUSSION}

The researcher would like to discuss the research results according to research purposes as follows:

- The background of stage costume business in Isan community revealed that it Being with the costume that people wore during a traditional festival and the costume that students wore during a 
performance such as a Thai dramatic art performance and a parade. The demand of these traditional costumes was a market segmentation which entrepreneurs supplied to customers. This phenomenon was consistent with a socio-cultural text of Supatra Suparp that described the cultural integration like this as a contemporary culture or the process of international culture adoption while the core culture was still maintained ${ }^{[2]}$. The majority of stage costume shops in 3 research areas such as Mahasarakham, Roi Et and Yasothon Province had carried forward more than 5 years. The entrepreneurs had an inspiration from the beauty that conceal into Thai culture and the requirement of stage costume of educational institutes so they established their shops in order to serve the taste of customers. The taste means the ability to judge the difference between good thing and bad thing and appreciate good thing ${ }^{[3]}$

- The situation and difficulties of stage costume business in Isan community at present revealed that the main difficulty was the entrepreneurs managed everything by themselves that caused a weakness of customer management. Stage costume business liked other businesses in 5 elements such as entrepreneurs, capital, costume, assistants and customers. The customers of stage costume business were a main factor that affected the situation and difficulties of stage costumer business; if the business could hold the more customers. Sequentially, a loss of stage costume, a lack of assistants, a lack of low cost stage costume sources, a competition in business and loan raising were the difficulties that caused the entrepreneurs could not expand their business

- The creation and development of a network of stage costume business in Isan community revealed that it was a step-by-step network. The entrepreneurs cooperated together in a small group in order to solve the difficulties concerning business management and afterwards they expanded into a larger group. At present, they have expanded their network from a local scale into a country scale

A willing network was necessary for the strength of the network. According to the results and the new findings, the researcher found 3 weaknesses of this network as follows:

- The differences of ages and qualifications of entrepreneurs caused some disagreement among them, especially disagreement concerning customer holding
- The differences of a gain from customer requirements caused each of Entrepreneurs created and developed stage costume on one's own way such as the entrepreneurs in Mahasarakham focused on a northeastern music and dance costume, while the entrepreneurs in Roi-Et focused on a parade and contemporary costume and in Yasothon focused on a traditional parade costume. Thus, the cooperation in creation and production of them was a main difficulty

- The competition for earnings among the entrepreneurs was very intense. Some of them sold stage costume at a cut-price rate, competed to hold customers and used a trick to hold customers through public relations

- The entrepreneurs were extreme independent. Sometime, stage costume was not enough for customers they ordered from other provinces instead of ordered from their province. So they had no chain of stage costume shops in their province

As mentioned before, each of stage costume businesses focused on customer services in order to serve an efficient service and a satisfaction for customers that was consistent with the concept of Lovelock $^{[4]}$. But in case of establishing cultural solidarity the entrepreneurs should link their business networks together that was consistent with the concept of McClelland, he mentioned that a personal success was a social success ${ }^{[5]}$.

\section{CONCLUSION}

According to the research results, the main difficulty of stage costume business in Isan society was the entrepreneurs could not expand their business into larger scales while the requirement of customers was increasing. The researcher would like to suggest that the research concerning the ways to establish and develop a service network of stage costume business is necessary. And the entrepreneurs should establish their business network in order to share all resources together and expand their business into larger scales base on appropriate culture that enhance the sustained occupations and earnings of community.

\section{ACKNOWLEDGEMENT}

The researchers wish to declare the deepest sense of thankfulness to the Research Institute of Northeast Art and Culture, Mahasarakham University. We also wish to express our thankful gratitude to any people 
from Muang District of Mahasarakham, Roi Et and Yasothon Province.

\section{REFERENCES}

1. Klamcharoen, A., 1991. An Aesthetic Thai Dramatic Art. Odien Store, Bangkok, ISBN: 974276-340-2, pp: 14.

2. Suparp, S., 1975. Thai Society and Culture. Thai Wattanapanit Publishing, Bangkok, ISBN: 9740838642, pp: 125-126.

3. Bourdieu, Pierre, 1989. Distinction: A Social Critique of the Judgement of Taste. Routledge, London, $\quad$ pp: 466. http://www.hup.harvard.edu/catalog/BOUDIX.html
4. Lovelock, C.H., 1988. Managing Services. Prentice Hall, London, pp: 118. http://oss.sagepub.com/cgi/pdf_extract/10/3/443

5. McClelland, D.C., 1961. The Achieving Society. Princeton, Van Nostrand, New Jersey, pp: 152. http://www.questia.com/PM.qst?a=o\&d=10299666 